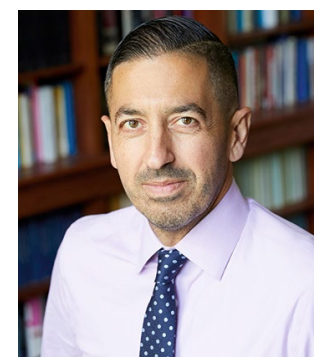

Credit: Kelly Davidson.

\title{
A better science for better decision-making in future crises
}

\author{
In fast-paced crises like COVID-19, making use of scientific discovery in policymaking is \\ challenging. We should learn the lessons of the current pandemic to make science a better \\ partner to decision-makers in future crises, Sandro Galea writes.
}

T he COVID-19 years have been banner years for science. Never before in recent memory has science broadly, and population health science specifically, been more in the forefront of public conversations. Scientists previously working in academic cloisters rocketed to rock star status, and what scientists might say became a guiding principle for much of what was discussed, written about and acted on in the policy sphere. And science has had some resounding success in guiding our response to COVID-19.

And yet, despite this elevated visibility of and respect for the science, COVID-19 has been a global tragedy. With more than 4.5 million deaths worldwide, COVID-19 became one of the leading causes of death in many countries in 2020, resulting in lowered life expectancies, often for the first time in decades. This raises crucial questions: what could science have done better? And how could this have better informed decision-making for health? I offer three potential answers to these questions.

First, the pace of COVID-19 challenged the course of scientific discovery, stretching what we do and how we do it. Science relies on the methodical application of rigorous methods of deduction to hypothesis-testing that advances our understanding of fundamental causal problems. This often means that much of what science does rests on study and counter-study, in which circumstances and conditions are altered until generalizable truth emerges. It requires us to allow for studies that contradict one another, to discuss why these contradictions have appeared and to synthesize this knowledge toward the generation of truths. These truths become what we know and can enter the public consciousness, serving as a foundation for policymaking.

When decision-makers needed information and insight in near real time during the epidemic, this completely upended the scientific process. Hypotheses were proposed and rapidly gained currency with scant testing. For example, the notion that SARS-CoV-2 spread through surface contact rapidly became received wisdom, even as more measured science soon suggested that this was an unlikely means of viral transmission. Ideas were placed on preprint servers without peer review, filling a knowledge vacuum, and in so doing became the only truth in town. The amplification of ideas through social media elevated flashy, reductive solutions over nuanced approaches that recognized the complexity of the messy world around us.

Unfortunately, this analysis does not point to ready solutions for better science in a time of crisis, other than the realization that new science, as we understand it, plays relatively little part during a crisis, and we should not pretend that it does. Rather, a crisis calls for the science that informs decision-making to be grounded in what we have previously known, and on the robustness of expert input based on prior knowledge.

Second, and building on the first, the greater weight that needs to be placed on expert knowledge - leaning on what we have previously understood and applying it to an evolving, uncertain present - requires us to inhabit a humility about what we know and about the boundaries of our knowledge. This epistemic humility should be a hallmark of the engagement of science in a time of uncertainty and crisis. Unfortunately, the COVID-19 era has seen plenty of examples of the opposite - epistemic arrogance and the assertive exposition of positions at the expense of the measured thinking that befits a time characterized principally by unknowns. The notion, for example, that we could attain 'zero COVID', or the elimination of the virus, was founded on a misunderstanding of both viral dynamics and history, but it gained sufficient weight through emphatic assertion as to become an important distraction from efforts to mitigate the pandemic through widespread vaccination.

When science leans so heavily into false certitude, it creates decisional cul-de-sacs for conscientious decision-makers who then do not have latitude for action that takes into account the broad range of other factors practical and political - that must equally occupy part of their decision-making architecture. Ironically, it is in times of crisis, when science knows least, that the words of scientists also weigh heaviest.

Third, emerging from the first two points, is that science related to the challenge of the moment is simply one piece of the decision-making puzzle and should both be recognized, and recognize itself, as such. When the science of COVID-19 transmission was still in its infancy, it became incumbent upon decision-makers to determine whether schools should be closed or remain open in the autumn of 2020. The immediate science of viral transmission - even as that was suggesting that there was limited risk to children or from children to caregivers - should have been only part of the input into decision-making. Equally valid was decades-old science showing that education is perhaps the most important driver of long-term health and demonstrating the social value of having children in school to allow adults, particularly women, to participate in the labour force. This also means that science needs to be open to disagreement about its place in the complex order of inputs that govern how we act, and must therefore allow space for reasonable scientists to argue over how what we know - limited as it is - can inform the larger picture.

There is little that can redeem a global tragedy such as COVID-19, but surely it is incumbent on us to, at the very least, learn from the mistakes of the moment to help to avoid similar errors in future. If a post-COVID-19 science can emerge improved, we could hope for science to be a more productive partner to decision-makers in the context of future contagions.

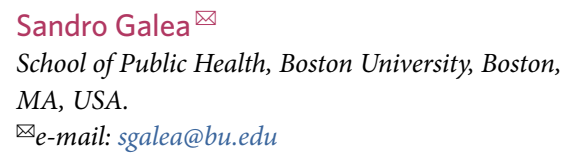

Published online: 21 October 2021 https://doi.org/10.1038/s41562-021-01226-1

Competing interests

The author declares no competing interests. 